\title{
Structural determination and population transfer of 4-nitroanisole by broadband microwave spectroscopy and tailored microwave pulses
}

\author{
Jack B. Graneek, ${ }^{1,2}$ Cristóbal Pérez, ${ }^{1,2}$ and Melanie Schnell ${ }^{1,2,3, a)}$ \\ ${ }^{1)}$ Max Planck Institute for the Structure and Dynamics of Matter, Luruper Chaussee 149, 22761 Hamburg, \\ Germany \\ ${ }^{2)}$ Deutsches Elektronen-Synchrotron DESY, Notkestraße 85, 22607 Hamburg, \\ Germany \\ ${ }^{3)}$ Christian-Albrechts-Universität zu Kiel, Max-Eyth-Str.1 24118 Kiel, Germany
}

\begin{abstract}
The rotational spectrum of 4-nitroanisole was recorded via chirped-pulse Fourier transform microwave spectroscopy in the frequency range of $2-8 \mathrm{GHz}$. The spectra of the parent molecule and all of its ${ }^{13} \mathrm{C}-,{ }^{15} \mathrm{~N}-$, and ${ }^{18} \mathrm{O}$-monosubstituted species in their natural abundance were assigned, and the molecular structure was determined using Kraitchmans equations as well as a least-square fitting approach. 4-nitroanisole has a large dipole moment of $6.15 \mathrm{D}$ along the a inertial axis and a smaller dipole moment of $0.78 \mathrm{D}$ along the b-axis. The large dipole moment component makes this molecule a potential candidate for deceleration experiments using static electric fields or electromagnetic radiation. Using tailored microwave pulses we investigate the possibility of transferring population between the rotational states of 4-nitroanisole. Such a technique could be applied to selectively increase the population for specific rotational states of interest, which are then accessible for further, more advanced experiments, such as deceleration.
\end{abstract}

\section{INTRODUCTION}

4-nitroanisole is considered a push and pull $\pi$ conjugated system as it contains an electron-withdrawing and an electron-donating group at opposite ends of the molecule. The nitro group has a negative inductive and mesomeric effect on the phenyl ring and is thus the withdrawing group. The methoxy group has a negative inductive effect and positive mesomeric effect. Usually the mesomeric effect is stronger than the inductive effect, so overall the methoxy group is electron-donating. Surfaceenhanced Raman spectroscopy (SERS) has been carried out on 4-nitroanisole and other similar "push-pull" systems ${ }^{1,2}$. These studies use SERS to investigate the adsorption of such systems on silver nano-particles and discuss their relevance for non-linear optical applications ${ }^{3,4}$. With the adsorption of 4-nitroanisole to an $\mathrm{Ag}$ colloid, the electronic structure of the molecule can be altered via internal charge transfer between the methoxy and nitro group. After laser irradiation $(\lambda=514.5 \mathrm{~nm})$ a catalytic reduction can occur resulting in further structural changes. Such changes can be better understood with a detailed knowledge of the system's structural properties. The sensitivity and high resolution of Fourier transform microwave (FTMW) spectroscopy can provide detailed information on a molecule's structure. As of yet 4-nitroanisole has not been investigated with such a technique and there is no experimental structure available for this molecule. Low resolution microwave spectroscopy has been used to study a number of molecules containing a methoxy group, including 4-nitroanisole ${ }^{5}$. Although this study was able to determine the rotational constants for 4-nitroanisole, it did not yield any structural parameters, such as bond lengths and angles,

a) Electronic mail: melanie.schnell@desy.de or information on the nuclear quadrupole coupling that arises due to the ${ }^{14} \mathrm{~N}$ nucleus. The high resolution and sensitivity offered by chirp-pulse Fourier transform microwave (CP-FTMW) spectroscopy allows for the determination of such structural parameters ${ }^{6,7}$. Other microwave spectroscopy studies carried out on nitrobenzene $^{8,9}$ and anisole ${ }^{10}$ were able to yield structural parameters that can be directly compared to those determined in this investigation. Such a comparison should provide more information regarding the influence of nitro and methoxy substituents on the phenyl ring.

In addition to structural determination of 4nitroanisole and understanding the effects of the substituents on the phenyl ring, we aim to investigate the potential of transferring population between selected rotational states with tailored microwave pulses. The large dipole moment to mass $(6.15 \mathrm{D}: 148.12 \mathrm{u})$ ratio and the ease at which it can be seeded into a molecular beam makes 4-nitroanisole an ideal candidate for experiments that aim to control and manipulate a molecule's motion using external electric ${ }^{11}$, magnetic ${ }^{12}$ or electromagnetic fields ${ }^{13-15}$. Effective motion manipulation, such as deceleration and trapping, of a molecule is dependent upon the interaction of an external field with a specific quantum state. In the last 15 years a number of techniques have been developed to achieve such control of small, polar molecules ${ }^{16}$. The effectiveness of the technique is limited by the size and complexity of the molecule under investigation. For example, Stark deceleration works on quantum states that increase in potential energy with increasing electric field strength, so-called low-field seeking states. Molecules that populate quantum states that are attracted to high field maxima (high-field seekers) are incompatible with current Stark deceleration techniques, instead more complex AG decelerators would be necessary to decelerate molecules in these states ${ }^{17}$. Generally larger, heavier molecules behave as high-field seekers at 
electric field strengths typically used in Stark deceleration and trapping experiments. However, Stark deceleration of low-field seeking states in $\mathrm{YbF}$ has been achieved with a travelling-wave decelerator using field strengths up to $37 \mathrm{kV} / \mathrm{cm}^{18}$. Furthermore, a recent study ${ }^{19}$ investigates the possibility of using a Stark decelerator on more complex polar molecules. For this technique to work it would be necessary to identify and selectively populate a rotational state that would behave as a low-field seeker up to electric field strengths of $50 \mathrm{kV} / \mathrm{cm}$ irrespective of the molecule's high density of rotational states ${ }^{20}$.

For somewhat larger/heavier molecules like 4nitroanisole the population distribution, even at temperatures between $1-3 \mathrm{~K}$, covers many rotational states due to small rotational constants on the order of a few $\mathrm{GHz}$ and less. The ability to increase the population of a rotational state of interest would be desirable not just for the previously mentioned study, but for all of the aforementioned deceleration techniques and experiments that require state-selected samples. Here, we employ tailored microwave pulses in a double-resonance scheme to drive and then observe the transfer of population from a well populated rotational state. Double-resonance experiments are more typically used to facilitate the analysis of complex rotational spectra by identifying the connectivity of energy levels ${ }^{21-26}$. Once the spectrum of 4nitroanisole has been assigned, three-level systems can be identified and double-resonance experiments applied. The emission signal detected after the application of tailored microwave pulses indicates to what extent population is transferred between rotational states, and also reconfirms the connectivity of transitions under investigation.

\section{EXPERIMENTAL DETAILS}

The broadband rotational spectrum of 4-nitroanisole was recorded using the Hamburg CP-FTMW spectrometer COMPACT. A detailed description of the set-up can be found in reference ${ }^{27}$. For details concerning recent improvements to the Hamburg spectrometer, such as the incorporation of the 'fast frame' approach ${ }^{28}$, refer to ref. ${ }^{29}$. CP-FTMW spectroscopy is a fast, robust and sensitive technique $^{30}$. A broadband microwave chirp is created using an arbitrary waveform generator (AWG), which is coupled into the vacuum chamber. The microwave excitation chirp is amplified by an adjustable travelling wave tube (TWT) amplifier. According to specifications, the TWT amplifier generates a maximum output power between $300 \mathrm{~W}$ at the edge of the frequency band to $600 \mathrm{~W}$ in the center (depending upon the specific microwave frequency). Horn antennas broadcast the microwave chirp into the vacuum chamber where it interacts with a sample of supersonically expanded, internally cold molecules. Polarization of the sample is achieved, and a macroscopic dipole moment is formed when the molecules are resonant with a frequency within the chirp. The decay of this

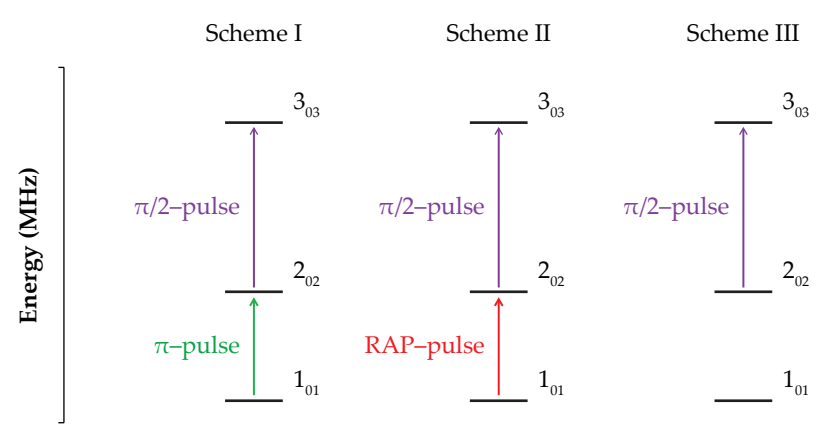

FIG. 1. Different pulse schemes employed for the population transfer experiments. The single frequency 2-pulse scheme (scheme I), the RAP 2-pulse scheme (scheme II), and the single frequency single pulse scheme (scheme III). Changes in the population distribution, brought about by a $\pi$-pulse or RAP-pulse, affects the signal intensity for the $3_{03} \leftarrow 2_{02}$ transition recorded after the $\pi / 2$-pulse. Comparing the signal measured for schemes I and II with scheme III should indicate to what extent population is redistributed.

macroscopic dipole moment is recorded as a free induction decay (FID) in the time domain with a high-speed digital oscilloscope. Phase stability allows for averaging high numbers of acquisitions in the time domain. In the case of 4-nitroanisole approximately 800,000 acquisitions were recorded, and after Fourier transformation a rotational spectrum with a signal to noise ratio of 1000:1 was produced. This is sufficient to observe the ${ }^{13} \mathrm{C}-,{ }^{15} \mathrm{~N}-$ , and ${ }^{18} \mathrm{O}$-isotopologues in their natural abundance of $1.1 \%, 0.36 \%$, and $0.2 \%$, respectively. Quantum-chemical calculations were performed in Gaussian ${ }^{31}$ and were later compared with the experimental data obtained.

For subsequent population transfer experiments the same experimental set-up is utilized. However, instead of the $2-8 \mathrm{GHz}$ chirp, tailored pulses of varying durations at single frequencies or $10 \mathrm{MHz}$ broad chirps are employed. In addition to this, two different amplifiers are included in the set-up: the TWT, and a $2 \mathrm{~W}$ solid-state amplifier. Different pulse schemes were designed (Fig. ??) and then applied. Detailed analysis of 4-nitroanisoles rotational spectrum allows for the identification of a candidate transition. Here the $2_{02} \leftarrow 1_{01}$ transition at 2183.17 $\mathrm{MHz}$ is chosen. This transition is ideal as both the upper and lower states are involved in a number of transitions that occur within the $2-8 \mathrm{GHz}$ frequency range covered by our spectrometer. Transitions that share an upper or lower state with the pump transition are referred to as 'signal' transitions. These signal transitions can be probed with a $\pi / 2$-pulse to establish how population is redistributed after the pump transition is exposed to a tailored microwave pulse.

When exciting rotational transitions with a single frequency pulse alone the effect of pulse duration on signal strength is well understood ${ }^{32,33}$. A $\pi$-pulse results in a population inversion for the transition and a significant reduction of the emission signal, whereas a $\pi / 2$-pulse re- 
sults in maximum coherence and thus a maximum emission signal. The emission signal is directly proportional to the population difference between the rotational states involved in a transition. This is also the case for excitation via a chirp pulse ${ }^{30}$. For 4 -nitroanisole, a $10 \mathrm{MHz}$ broad chirp amplified by the TWT amplifier at 100\% gain is within the rapid adiabatic passage (RAP) regime and is henceforth referred to as the RAP-pulse. This regime will be discussed in more detail in section III A. Similarly to the $\pi$-pulse, the RAP-pulse is also used to transfer population between states. Both schemes I and II, refer to Fig. 1, aim to alter the population distribution of states involved in the selected pump transition, and then probe a signal transition with a $\pi / 2$-pulse. The third scheme acts as a reference to the first and second, a $\pi / 2$ pulse that probes a signal transition alone. Comparing the intensities measured at a signal transition frequency for the different schemes should indicate the extent to which population is being transferred between the pump transition's rotational states.

\section{RESULTS AND DISCUSSION}

\section{A. Rotational spectrum of 4-nitroanisole}

The broadband rotational spectra of 4-nitroanisole measured with a solid-state amplifier, the TWT at $100 \%$ and $50 \%$ gain, as well as the corresponding fit are displayed in Fig. 2. The measured intensities vary considerably depending on the gains employed. To rationalise this behaviour it is necessary to consider two different regimes of fast passage phenomena, the rapid adiabatic passage (RAP) and the linear fast passage (LFP). The large dipole moment of 4-nitroanisole means that for measurements taken at $100 \%$ gain the RAP regime best describes transient effects during the chirp. In this regime, transfer and inversion of the population for a rotational transition can occur reducing coherence and therefore the intensity recorded. Even stepwise multi-resonance effects can occur when using a chirp that further affects the observed transition intensities, which explains the gradual increase in intensity from $2-8 \mathrm{GHz}$ at $100 \%$ gain. This was previously observed for benzonitrile ${ }^{27}$, which also has a large dipole moment $\left(\mu_{a}=4.52 \mathrm{D}\right)$. For the LFP regime, the chirp has a negligible effect on the population difference, instead coherence dominates resulting in increased transition intensities. Experiments carried out at $50 \%$ gain are within this LFP regime, hence the stronger intensities observed and better agreement with the predicted intensities from the PGOHPER program ${ }^{34}$. Line strengths predicted within PGOPHER rely on the Boltzmann distribution of a population at a selected rotational temperature, in this case $1 \mathrm{~K}$, and ignore other effects that might alter a system's population distribution. From the intensities of the respective a-, b-, c-type transitions we can estimate a ratio of 6.75:1:0 for the dipole moment components, which is in good agreement with those pre-

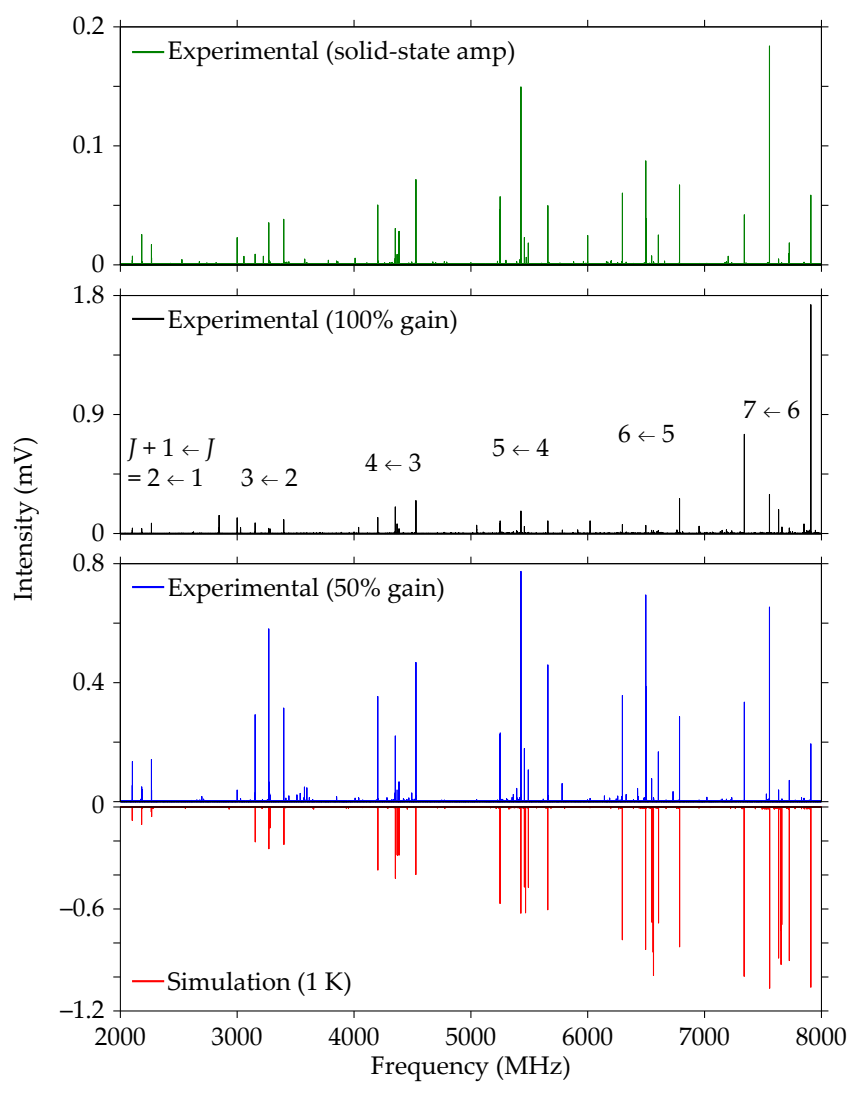

FIG. 2. Rotational spectrum of 4-nitroanisole; the upper traces show the experimental spectrum recorded at three different levels of amplification. According to specifications, using the TWT amplifier at $100 \%$ gain corresponds to a frequency dependent output power of at least $300 \mathrm{~W}$, whereas a $50 \%$ gain gives an output power of approximately $75 \mathrm{~W}$. The solid-state amplifier provides approximately $2 \mathrm{~W}$ output power. The lower trace represents a simulation using the fitted spectroscopic parameters reported in Table I.

dicted via calculations.

Structure optimization calculations were carried out using different basis sets in combination with the B3LYP hybrid functional including and excluding Grimmes's empirical dispersion, as well as Møller-Plesset perturbation theory (MP2). While we observe good agreement between the experimental and calculated rotational constants, the nuclear quadrupole coupling constants largely deviate for the MP2 calculations (see Table ?? of the supplementary material). This is independent of the molecular structure we used as basis of our calculations so that it seems to be intrinsic to the calculation. We included the values in Table ?? of the supplementary material for completeness. The obtained rotational parameters, including the nuclear quadrupole coupling constants, from the B3LYP calculations are listed in Table I. After assignment of the strong a-type and weaker b-type transitions, the quantum-chemical rotational parameters could be directly compared to those determined experimentally. This assignment was implemented with the 
TABLE I. Spectroscopic constants of 4-nitroanisole determined experimentally and via quantum-chemical calculations. The value in square brackets was taken directly from calculations.

\begin{tabular}{ccccc}
\hline Parameter & Experiment & $\begin{array}{c}\text { B3LYP/ } \\
\text { aug-cc-pVTZ }\end{array}$ & $\begin{array}{c}\text { B3LYP/ } \\
\text { aug-cc-pVTZ } \\
\text { (GD3BJ })\end{array}$ & $\begin{array}{c}\text { B3LYP/ } \\
\text { def-TZVP) } \\
\text { (GD3BJ })\end{array}$ \\
\hline $\mathrm{A}(\mathrm{MHz})$ & $3533.8097(5)$ & 3565.90 & 3563.30 & 3565.43 \\
$\mathrm{~B}(\mathrm{MHz})$ & $587.03009(5)$ & 586.25 & 588.15 & 588.07 \\
$\mathrm{C}(\mathrm{MHz})$ & $505.37812(5)$ & 505.09 & 506.45 & 506.44 \\
$\mathrm{D}_{K}(\mathrm{kHz})$ & $0.33(8)$ & - & - & - \\
$\mathrm{D}_{J K}(\mathrm{kHz})$ & $-0.031(5)$ & - & - & - \\
$\mathrm{D}_{J}(\mathrm{kHz})$ & $0.006(1)$ & - & - & - \\
$\chi_{a a}(\mathrm{MHz})$ & $-1.164(2)$ & -1.2409 & -1.2494 & -1.2813 \\
$\chi_{b b-c c}(\mathrm{MHz})$ & $-0.569(3)$ & -1.0179 & -1.0172 & -1.0495 \\
$\chi_{a b}(\mathrm{MHz})$ & {$[-0.1145]$} & -0.1145 & -0.1168 & -0.1200 \\
$\mu_{a}(\mathrm{D})$ & - & 6.15 & 6.14 & 6.09 \\
$\mu_{b}(\mathrm{D})$ & - & 0.78 & 0.78 & 0.78 \\
$\mu_{c}(\mathrm{D})$ & - & 0 & 0 & 0 \\
$\mathrm{~N}_{\text {lines }}$ & 169 & - & - & - \\
$\sigma(\mathrm{kHz})$ & 4.9 & - & - & - \\
\hline
\end{tabular}

program PGOPHER. The rotational quantum numbers involved in the assigned transitions range from $J=1 \mathrm{up}$ to $J=11$. In total 169 lines were assigned for the parent molecule with an average error of the fit of $4.9 \mathrm{kHz}$. A closer look at the quadrupole coupling splitting due to the nitrogen atom of the nitro group can be found in Fig. 3. The observed hyperfine structure is due to the coupling of nitrogen's nuclear charge density with the electric potential generated by the electrons and other nuclei. Nitrogen's nuclear spin $\left(\mathrm{I}\left({ }^{14} \mathrm{~N}\right)=1\right)$ couples with the molecular rotational angular momentum J. Consequently the total angular momentum of 4-nitroanisole is $\mathrm{F}$ rather than J, and the new angular momentum quantum numbers are:

$$
F=J+I, J+I-1, J+I-2, \ldots,|J-I|
$$

The experimentally determined quadrupole coupling constants for 4-nitroanisole are very similar to those determined for the ground state of nitrobenzene, where $\chi_{a a}=$ $-1.1589(24) \mathrm{MHz}$ and $\chi_{b b-c c}=-0.5199(68) \mathrm{MHz}^{35}$. Nuclear quadrupole coupling constants are sensitive to the local electronic environment, as well as the orientation of the principal axis system for the molecule. A difference in the nuclear quadrupole coupling constants of only 5 and $49 \mathrm{kHz}$ for $\chi_{a a}$ and $\chi_{b b-c c}$, respectively, would suggest that the addition of a para-methoxy group to nitrobenzene has only a small effect on the local electronic environments of the respective nitrogen atoms, or the orientation of the principal axis system. Initially, we would have expected a larger difference between the nuclear quadrupole coupling constants as the additional methoxy group (a) introduces an electron donating effect and (b) re-positions the centre of mass and the inertial coordinate system of 4 -nitroanisole relative to nitrobenzene. The closeness of the nuclear quadrupole coupling constants leads to two potential conclusions:

1. The electron donating effect of the para-methoxy group has little impact on the electronic environment of the nitrogen atom due to the only weak interaction via the phenyl ring, or the re-positioning of the coordinate system works to counteract this electron donating effect.

2. The nitrogen atom is a weakly coupling quadrupole nucleus, and therefore not a sufficiently sensitive probe for such effects.

To gain more insight into the influence of nitroanisole's substituents on the phenyl ring more structural information is required.

The high sensitivity of the spectrometer allows for the observation of singly substituted ${ }^{13} \mathrm{C},{ }^{15} \mathrm{~N}$ and ${ }^{18} \mathrm{O}$ isotopologues of 4-nitroanisole in their natural abundance. The lines assigned to the isotopologues for the $J_{K a, K c} \leftarrow J_{K a, K c}=3_{12} \leftarrow 2_{12}$ transition are displayed in Fig. 4. Here, it is worth noting the absence of hyperfine structure observed for the ${ }^{15} \mathrm{~N}$ isotopologue as $I\left({ }^{15} \mathrm{~N}\right)=1 / 2$. The number of lines assigned and the rotational constants derived from the fits for each isotopologue are summarized in Table II. With this information, the $r_{s}$ coordinates for each atom (excluding the hydrogen atoms) of 4-nitroanisole were determined using Kraitchmans equations ${ }^{36}$ for both planar and non-planar molecules, implemented with the KRA program ${ }^{37}$. As expected, the non-planar approach is more appropriate as the inertial defect $\left(\Delta=I_{c}-I_{a}-I_{b}\right)$ of 4-nitroanisole 
TABLE II. Rotational constants determined from the assignment of each isotopologue. Also included are the number of lines assigned for each isotopologue $\left(\mathrm{N}_{\text {lines }}\right)$ and the average error of the fit $(\sigma)$, which are needed for the subsequent Kraitchman calculations used to determine the substituted $\left(r_{s}\right)$ molecular structure.

\begin{tabular}{ccccccc}
\hline Parameter & Parent & $\mathrm{C}_{1}$ & $\mathrm{C}_{2}$ & $\mathrm{C}_{3}$ & $\mathrm{C}_{4}$ & $\mathrm{C}_{5}$ \\
\hline $\mathrm{A}(\mathrm{MHz})$ & $3533.8097(5)$ & $3533.39(9)$ & $3502.06(9)$ & $3507.38(9)$ & $3532.35(7)$ & $3486.44(9)$ \\
$\mathrm{B}(\mathrm{MHz})$ & $587.03009(5)$ & $586.3210(3)$ & $586.9976(3)$ & $586.1808(3)$ & $585.0571(3)$ & $586.4743(3)$ \\
$\mathrm{C}(\mathrm{MHz})$ & $505.37812(5)$ & $504.8519(3)$ & $504.7036(3)$ & $504.2258(2)$ & $503.8874(3)$ & $503.9885(2)$ \\
$\mathrm{N}_{\text {lines }}$ & 169 & 45 & 46 & 41 & 45 & 39 \\
$\sigma(\mathrm{kHz})$ & 4.9 & 3.7 & 4.0 & 4.2 & 5.0 & 3.2 \\
\hline Parameter & $\mathrm{C}_{6}$ & $\mathrm{C}_{15}$ & $\mathrm{~N}_{11}$ & $\mathrm{O}_{12}$ & $\mathrm{O}_{13}$ & $\mathrm{O}_{14}$ \\
\hline $\mathrm{A}(\mathrm{MHz})$ & $3493.07(10)$ & $3523.27(8)$ & $3533.87(12)$ & $3494.18(13)$ & $3461.31(8)$ & $3523.41(10)$ \\
$\mathrm{B}(\mathrm{MHz})$ & $586.8905(3)$ & $576.7990(2)$ & $582.8467(3)$ & $573.8157(4)$ & $575.2556(4)$ & $574.7626(4)$ \\
$\mathrm{C}(\mathrm{MHz})$ & $504.4455(3)$ & $497.5745(2)$ & $502.2696(4)$ & $494.7644(3)$ & $495.1794(4)$ & $496.0471(3)$ \\
$\mathrm{N}_{\text {lines }}$ & 34 & 44 & 18 & 16 & 16 & 16 \\
$\sigma(\mathrm{kHz})$ & 3.5 & 4.0 & 3.4 & 4.4 & 4.0 & 6.5 \\
\hline
\end{tabular}

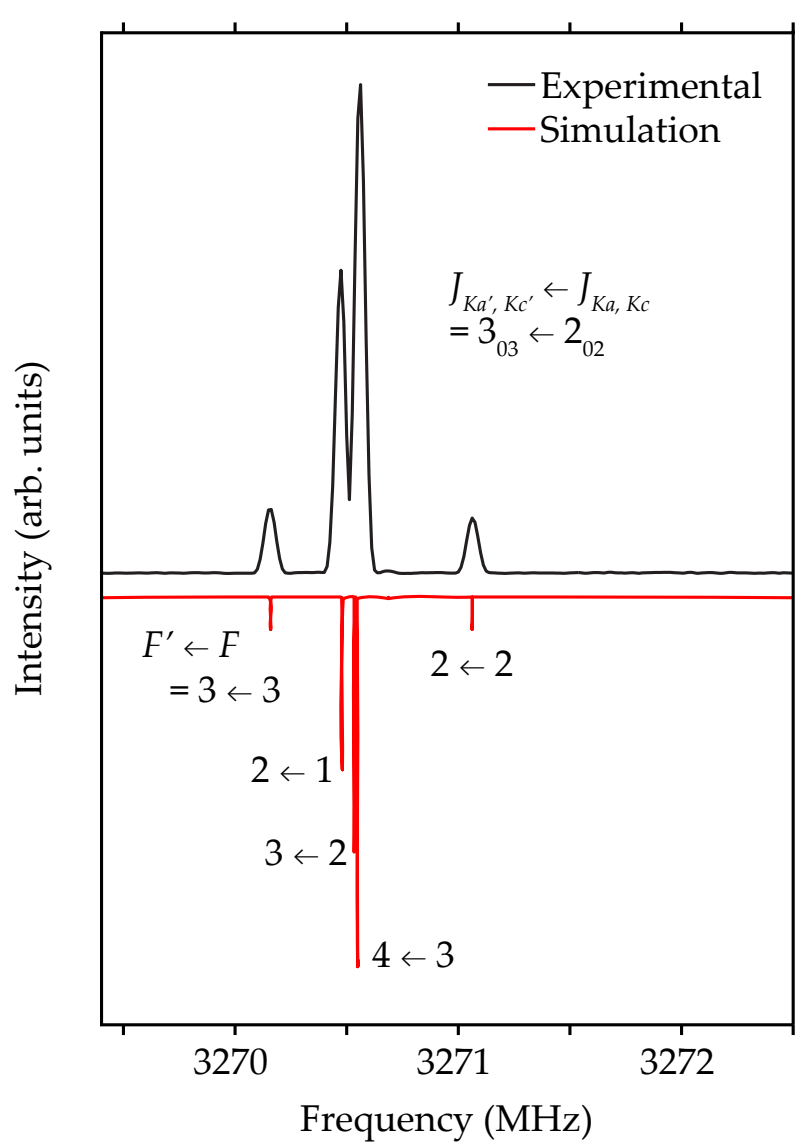

FIG. 3. Nuclear quadrupole coupling splitting for the $3_{03} \leftarrow$ $2_{02}$ rotational transition due to the ${ }^{14} \mathrm{~N}$ atom in 4-nitroanisole measured at $50 \%$ gain. The $F$ quantum numbers are also displayed. is $-3.91 \mu \AA^{2}$. Anisole displays a similar inertial defect of $-3.41 \mu \AA^{2}$ and was also treated with the non-planar approach $^{38}$. For nitrobenzene an inertial defect of +0.249 $\mu \AA^{2}$ was determined ${ }^{8}$. The absence of the methoxy group and therefore the out-of-plane hydrogen atoms results in an inertial defect with a magnitude and sign expected of planar molecules with small amplitude vibrations.

Regardless of the approach employed, evaluation of the $r_{s}$ structure for 4-nitroanisole was complicated by the closeness of several atoms to the inertial axes, refer to Fig. 5(a). When adopting the non-planar approach, atoms $\mathrm{N}_{11}, \mathrm{O}_{12}$ and $\mathrm{O}_{14}$ exhibit imaginary components along the $\mathrm{c}$ inertial axis. For the planar approach only the $\mathrm{N}_{11}$ atom displayed an imaginary component, this time along the $\mathrm{b}$ inertial axis. As a result, the internal coordinates of these atoms could not be evaluated. This behaviour has also had an impact on the evaluated $r_{s}$ structures of the phenyl ring, which is particularly evident for parameters that include atoms $\mathrm{C}_{1}, \mathrm{C}_{2}$ and $\mathrm{C}_{6}$ (refer to Table III). The planar approach does, however, provide reliable structural information on the substituents of 4-nitroanisole. Although the $\mathrm{N}_{11}$ position could not be evaluated, the distance between the oxygen atoms of the nitro group could be determined. Millen and Morton ${ }^{39}$ encountered similar problems when determining the $r_{s}$ structure of nitric acid. As the nitrogen atom lies so close to the molecule's centre of mass, Kraitchman calculations yielded a nitrogen position that altered the resonance structure of the nitro group. The $\mathrm{N}-\mathrm{O}$ bonds differed in length by almost $0.04 \AA$, and consequently the nitrogen position was readjusted to accommodate for the expected resonance structure. For comparisons to other molecules that contain a nitro group, Millen and Morton utilized the distance between the oxygen atoms, where their determined value was independent of any structural assumptions made. Our value for the $\mathrm{O} \cdots \mathrm{O}$ distance from Kraitchman calculations is 

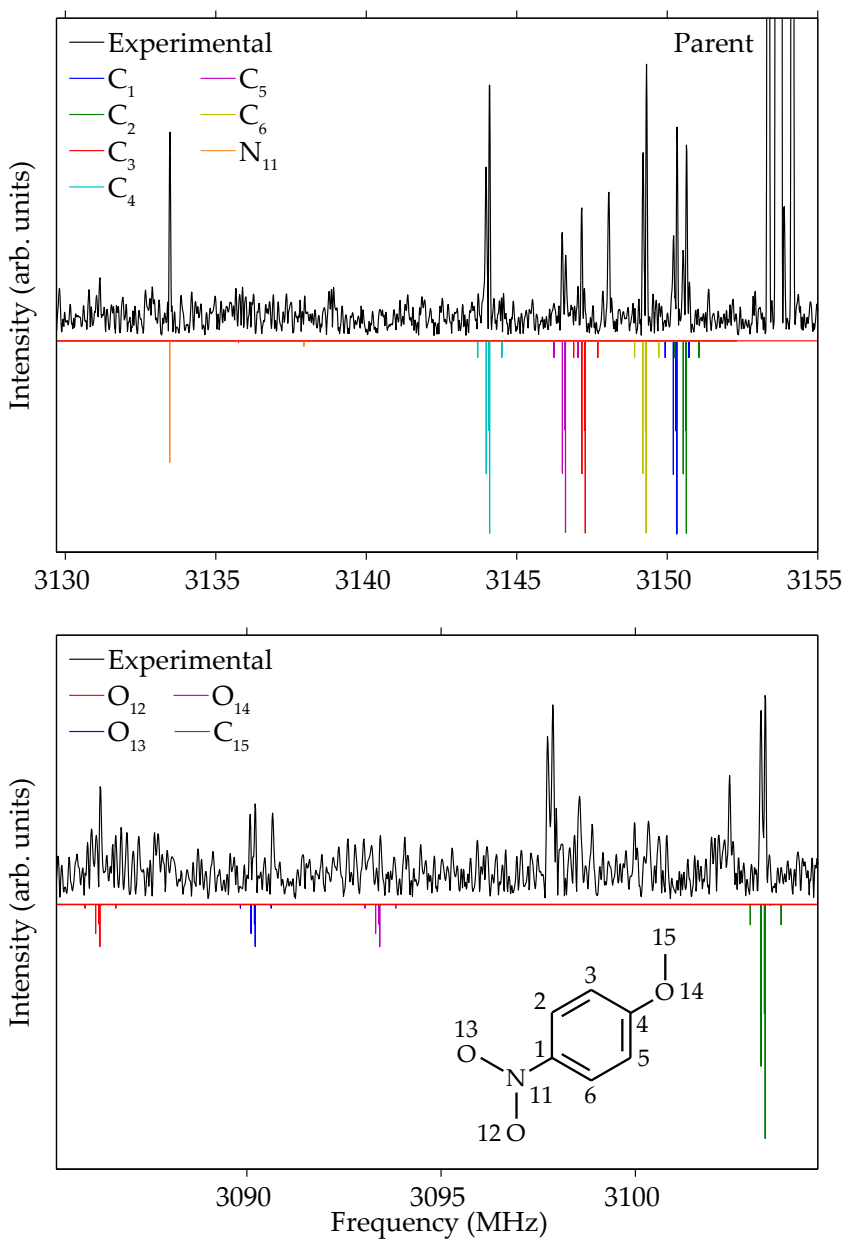

FIG. 4. Satellite lines of singly substituted ${ }^{13} \mathrm{C},{ }^{15} \mathrm{~N},{ }^{18} \mathrm{O}$ isotopologues and the parent lines for the $J_{K a, K c} \leftarrow J_{K a, K c}=$ $3_{12} \leftarrow 2_{12}$ rotational transition. The ${ }^{18} \mathrm{O}_{14}$ isotopologue is not assigned here as the corresponding transition intensity is too weak, but has been reliably assigned to transitions with stronger intensities. Also included is the molecular structure and atom labelling of 4-nitroanisole.

2.171(3) A, which although smaller than that determined for nitric acid, 2.190(3) $\AA^{39}$, matches the distance for nitrobenzene $(2.171 \AA)$ referred to by Cox and Waring in their study of the structure of nitromethane ${ }^{40}$.

For the methoxy group, $r_{s}$ bond lengths determined via the planar approach can be directly compared to those obtained for anisole ${ }^{38}$. Once again, evaluation of the $r_{s}$ structure was complicated by the positions of some atoms with respect to the inertial axes, so to further investigate the structure of anisole, Desyatnyk et al. ${ }^{38}$ performed a mass-dependent structural fit to yield the $r_{m}^{(1)}$ geometry less susceptible to the effects that reduce the accuracy of the $r_{s}$-coordinates. The mass-dependent structural fit typically generates structures closer to the equilibrium structure as the method takes the inertial defect into account. This approach has been applied to a number of molecules, including the water heptamer ${ }^{28}$
TABLE III. Experimentally determined and calculated bond lengths of 4-nitroanisole; $r_{s}$-structure (Kraitchmans planar and non-planar equations), $r_{m}^{(1)}$-structure (mass-dependent least-square fit), $r_{e}$-structure (B3LYP/aug-cc-pVTZ).

\begin{tabular}{ccccc}
\hline $\begin{array}{c}\text { Bond } \\
\text { lengths }\end{array}$ & $\begin{array}{c}\text { Planar } \\
r_{s}(\AA)\end{array}$ & $\begin{array}{c}\text { Non-planar } \\
r_{s}(\AA)\end{array}$ & $r_{m}^{(1)}(\AA)$ & $\begin{array}{c}\text { B3LYP } \\
r_{e}(\AA)\end{array}$ \\
\hline $\mathrm{C}_{1}-\mathrm{C}_{2}$ & $1.504(17)$ & $1.474(17)$ & $1.386(6)$ & 1.386 \\
$\mathrm{C}_{2}-\mathrm{C}_{3}$ & $1.340(7)$ & $1.326(9)$ & $1.400(7)$ & 1.387 \\
$\mathrm{C}_{3}-\mathrm{C}_{4}$ & $1.412(9)$ & $1.406(7)$ & $1.398(4)$ & 1.398 \\
$\mathrm{C}_{4}-\mathrm{C}_{5}$ & $1.405(8)$ & $1.408(6)$ & $1.402(4)$ & 1.402 \\
$\mathrm{C}_{5}-\mathrm{C}_{6}$ & $1.360(3)$ & $1.353(9)$ & $1.394(8)$ & 1.378 \\
$\mathrm{C}_{6}-\mathrm{C}_{1}$ & $1.295(18)$ & $1.344(18)$ & $1.385(6)$ & 1.393 \\
& & & & \\
$\mathrm{C}_{1}-\mathrm{N}_{11}$ & - & - & $1.475(3)$ & 1.463 \\
$\mathrm{~N}_{11}-\mathrm{O}_{12}$ & - & - & $1.220(3)$ & 1.225 \\
$\mathrm{~N}_{11}-\mathrm{O}_{13}$ & - & - & $1.230(3)$ & 1.225 \\
$\mathrm{O}_{12} \cdots \mathrm{O}_{13}$ & $2.171(3)$ & - & $2.167(3)$ & 2.166 \\
$\mathrm{C}_{4}-\mathrm{O}_{14}$ & $1.359(2)$ & - & $1.356(2)$ & 1.352 \\
$\mathrm{O}_{14}-\mathrm{C}_{15}$ & $1.424(5)$ & - & $1.414(4)$ & 1.430 \\
\hline
\end{tabular}

and cinnamaldehyde ${ }^{6}$. A least-square fit of the structure to the rotational constants as well as an additional parameter was performed and implemented in the STRFIT $\operatorname{program}^{37}$. The extra parameter $\left(c_{a}=0.0596(4) \mathrm{u}^{1 / 2} \AA\right)$ accounts for the isotope-dependent rovibrational contribution to the moments of inertia of the molecule ${ }^{41}$.

A direct comparison of the structural parameters obtained from each approach is given in Tables III and IV. The quantum-chemical theoretical predictions, which correspond to a hypothetical equilibrium structure $\left(r_{e}\right)$ at a potential energy minimum without zero-point vibration, are in much better agreement with the $r_{m}^{(1)}$ structure than the $r_{s}$ structure, this is also visible from Figure 5(b).

The methoxy group of 4-nitroanisole behaves as an electron-donating group, contributing electron density to the phenyl ring. Coupled with the electron-withdrawing effect of the nitro group, we observe a reduction in the $\mathrm{C}_{4}-\mathrm{O}_{14}$ bond length compared to the $r_{s}$ and $r_{m}^{(1)}$ structures of anisole, refer to Table $\mathrm{V}$. The reduction in the $\mathrm{C}-\mathrm{O}$ bond length also causes the $\angle \mathrm{CCO}$ angle to increase due to steric effects. For the reasons described above, the evaluation of the $r_{s}$ structures for 4-nitroanisole complicates comparisons to the nitro group of nitrobenzene. The $r_{s}(\mathrm{O} \cdots \mathrm{O})$ distance of 4-nitroanisole and nitrobenzene is essentially the same, but the lack of any other $r_{s}$ parameters for the nitro group of 4-nitroanisole forces us to rely more on the determined $r_{m}^{(1)}$ parameters. There is little variation in the $\mathrm{N}-\mathrm{O}$ bond length obtained irrespective of the method used to evaluate this distance; however, there is a rather large alteration in the bond that connects the nitro group to the phenyl ring. Here, 
TABLE IV. Experimentally determined and calculated bond angles of 4-nitroanisole; $r_{s}$-structure (Kraitchmans planar and non-planar equations), $r_{m}^{(1)}$-structure (mass-dependent leastsquare fit), $r_{e}$-structure (B3LYP/aug-cc-pVTZ).

\begin{tabular}{|c|c|c|c|c|}
\hline $\begin{array}{l}\text { Bond } \\
\text { angles }\end{array}$ & $\begin{array}{l}\text { Planar } \\
r_{s}(\AA)\end{array}$ & $\begin{array}{c}\text { Non-planar } \\
r_{s}(\AA)\end{array}$ & $r_{m}^{(1)}(\AA)$ & $\begin{array}{l}\text { B3LYP } \\
r_{e}(\AA)\end{array}$ \\
\hline$\angle \mathrm{C}_{1} \mathrm{C}_{2} \mathrm{C}_{3}$ & $117.95(48)$ & $118.42(53)$ & $118.94(31)$ & 119.7 \\
\hline$\angle \mathrm{C}_{2} \mathrm{C}_{3} \mathrm{C}_{4}$ & $118.98(24)$ & $119.50(32)$ & $119.29(25)$ & 119.7 \\
\hline$\angle \mathrm{C}_{3} \mathrm{C}_{4} \mathrm{C}_{5}$ & $120.49(13)$ & $120.05(29)$ & $120.57(22)$ & 119.9 \\
\hline$\angle \mathrm{C}_{4} \mathrm{C}_{5} \mathrm{C}_{6}$ & $120.51(27)$ & $120.10(54)$ & $120.16(23)$ & 120.3 \\
\hline$\angle \mathrm{C}_{5} \mathrm{C}_{6} \mathrm{C}_{1}$ & $120.44(44)$ & $118.87(88)$ & $118.30(36)$ & 119.29 \\
\hline$\angle \mathrm{C}_{6} \mathrm{C}_{1} \mathrm{C}_{2}$ & $121.62(29)$ & $120.30(48)$ & $122.74(42)$ & 121.13 \\
\hline$\angle \mathrm{C}_{2} \mathrm{C}_{1} \mathrm{~N}_{11}$ & - & - & $118.25(38)$ & 119.4 \\
\hline$\angle \mathrm{C}_{6} \mathrm{C}_{1} \mathrm{~N}_{11}$ & - & - & $119.01(40)$ & 119.5 \\
\hline$\angle \mathrm{C}_{1} \mathrm{~N}_{11} \mathrm{O}_{12}$ & - & - & $117.78(25)$ & 117.8 \\
\hline$\angle \mathrm{C}_{1} \mathrm{~N}_{11} \mathrm{O}_{13}$ & - & - & $117.90(24)$ & 117.9 \\
\hline$\angle \mathrm{O}_{12} \mathrm{~N}_{11} \mathrm{O}_{13}$ & - & - & $124.31(10)$ & 124.3 \\
\hline$\angle \mathrm{C}_{3} \mathrm{C}_{4} \mathrm{O}_{14}$ & $124.08(57)$ & - & $124.65(30)$ & 124.7 \\
\hline$\angle \mathrm{C}_{4} \mathrm{O}_{14} \mathrm{C}_{15}$ & $118.04(48)$ & - & $118.07(30)$ & 118.6 \\
\hline$\angle \mathrm{C}_{5} \mathrm{C}_{4} \mathrm{O}_{14}$ & $115.43(63)$ & - & $114.79(31)$ & 115.4 \\
\hline
\end{tabular}

a)

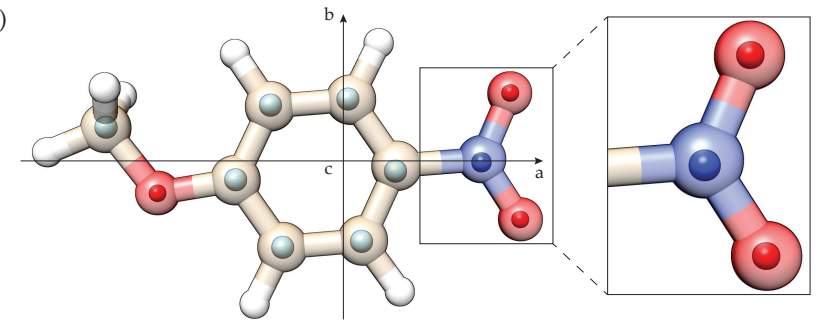

b)

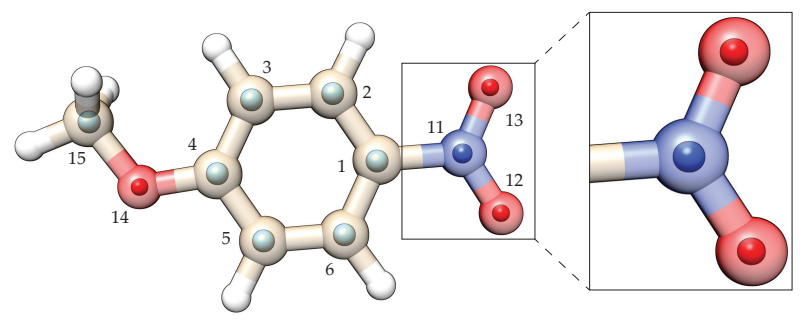

FIG. 5. Comparison of the calculated (background) and the experimentally determined (foreground, spheres) atom positions, excluding hydrogen. Calculated atom positions obtained from B3LYP/aug-cc-pVTZ calculations. Experimental atom positions determined via (a) non-planar Kraitchman equations $\left(r_{s}\right.$-structure), (b) mass-dependent least-square fit $\left(r_{m}^{(1)}\right.$-structure). Also included is a reference to the inertial axis frame in (a) and the atom labels in (b).<smiles>C=C=C1C=CC(=[O+]C)C=C1</smiles>

FIG. 6. Resonant forms of 4-nitroanisole. Left is the benzoid form, right the quinoid zwitterion form.

the $r_{m}^{(1)}(\mathrm{C}-\mathrm{N})$ bond length of 4-nitroanisole is more than $0.01 \AA$ shorter than the distances reported in gas-phase electron diffraction (GED) $)^{42}$ and microwave ${ }^{8,43}$ studies of nitrobenzene. As the nitro group withdraws electron density from the phenyl ring this encourages the donation of more electron density from the methoxy group. Electronic charge transfer from the methoxy to the nitro group through the $\pi$-conjugated system has been confirmed by UV absorption of 4-nitroanisole in different solvents ${ }^{2}$. A result of this charge transfer process is that two resonant forms of 4-nitroanisole can exist in solution; a benzenoid form and a quinoid form (Fig. 6). There is no noticeable effect on the $r_{m}^{(1)}$ bond lengths of the phenyl ring, which within the errors are very similar. The reduction of the $\mathrm{C}-\mathrm{O}$ and $\mathrm{C}-\mathrm{N}$ bond lengths of 4-nitroanisole compared to the same bond found in nitrobenzene and anisole, respectively, supports the migration of electron density across the phenyl ring, which is consistent with the "push-pull" picture of 4-nitroanisole.

\section{B. Population transfer}

To observe the transfer of population between rotational states we employed different pulse schemes with varying pulse durations and bandwidths (Fig. 1). The transition we focus on in this experiment is the $2_{02} \leftarrow 1_{01}$ transition, which is a strong a-type transition observed at $2183.17 \mathrm{MHz}$. Nutation measurements were recorded for this and any other transition within the $2-8 \mathrm{GHz}$ frequency range that involved either the upper or lower state of our focus transition, the so-called signal transitions. These measurements record the signal intensity for a transition of interest gradually increasing the pulse duration in order to determine the respective $\pi$-pulse and $\pi / 2$-pulse durations. This is necessary for the observation of population transfer effects. Originally all of the nutation measurements were carried out using the TWT amplifier. However, due to sideband formation ${ }^{27,44}$ it became necessary to work with the $2 \mathrm{~W}$ solid-state amplifier, where such effects are much less pronounced.

The signal detected after excitation of a rotational transtion using a single frequency microwave pulse is directly proportional to the dipole moment, the electric field strength, and the population difference between the 
TABLE V. Structural parameters determined via gas-phase electron diffraction (GED) ${ }^{42}$ and microwave spectroscopy $\left(r_{s}\right.$ and $\left.r_{m}^{(1)}\right)$ for the substituents of both nitrobenzene $e^{8,43}$ and anisole ${ }^{38}$, compared with those determined for 4-nitroanisole in this work.

${ }^{a}$ Bond lengths in $\AA$ and angles in degrees.

${ }^{b}$ Average of the two $\mathrm{N}-\mathrm{O}$ bond lengths obtained.

${ }^{c}$ Value referred to by Cox and Waring ${ }^{40}$.

\begin{tabular}{|c|c|c|c|c|c|c|}
\hline \multirow{2}{*}{ Parameter $^{a}$} & \multicolumn{2}{|c|}{ Nitrobenzene } & \multicolumn{2}{|c|}{ Anisole } & \multicolumn{2}{|c|}{ 4-Nitroanisole } \\
\hline & GED & $r_{s}$ & $r_{s}$ & $r_{m}^{(1)}$ & $r_{s}$ & $r_{m}^{(1)}$ \\
\hline $\mathrm{C}-\mathrm{N}$ & $1.486(4)$ & $1.4916(17)$ & - & - & - & $1.475(3)$ \\
\hline $\mathrm{N}-\mathrm{O}$ & $1.223(3)$ & $1.2273(2)$ & - & - & - & $1.225(3)^{b}$ \\
\hline $\mathrm{O} \cdots \mathrm{O}$ & - & $2.171^{c}$ & - & - & $2.171(3)$ & $2.167(3)$ \\
\hline$\angle \mathrm{ONO}$ & $125.3(2)$ & $124.35(1)$ & - & - & - & $124.31(10)$ \\
\hline $\mathrm{C}-\mathrm{O}$ & - & - & $1.381(4)$ & $1.372(3)$ & $1.359(2)$ & $1.356(2)$ \\
\hline $\mathrm{O}-\mathrm{C}$ & - & - & $1.418(3)$ & $1.417(2)$ & $1.424(5)$ & $1.414(4)$ \\
\hline$\angle \mathrm{CCO}$ & - & - & $114.0(5)$ & $114.8(3)$ & $124.08(57)$ & $124.65(30)$ \\
\hline$\angle \mathrm{COC}$ & - & - & $117.2(4)$ & $117.5(3)$ & $118.04(48)$ & $118.07(30)$ \\
\hline
\end{tabular}

a)

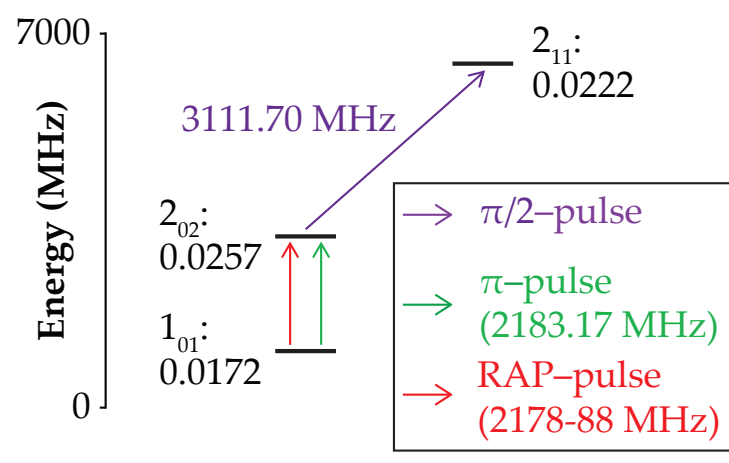

c)

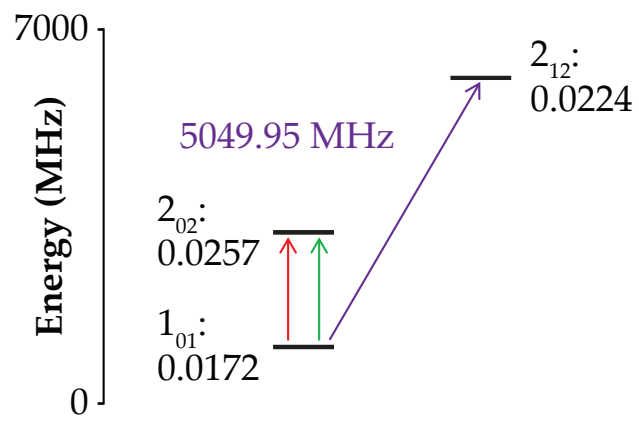

b)

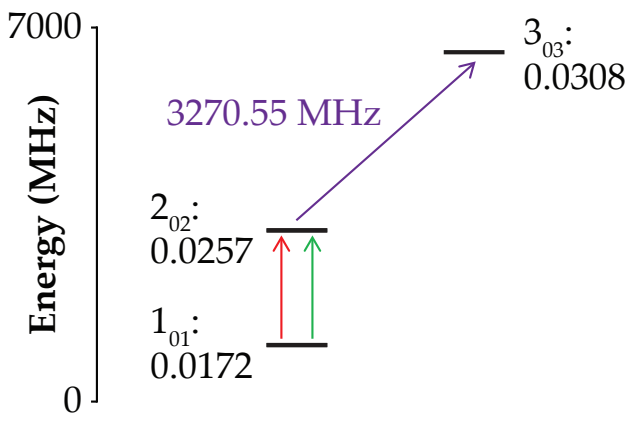

d)

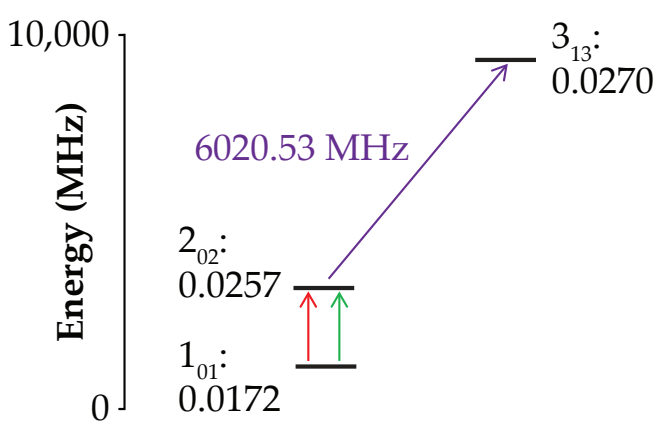

FIG. 7. Schematic of each transition connected to the $2_{02} \leftarrow 1_{01}$ transition. Approximate population numbers at $1 \mathrm{~K}$ follow the rotational state labels and were determined in PGOPHER. A total population of one was distributed over all the rotational levels up to $J=30$. These numbers are included to better illustrate how a 2-pulse scheme would affect the population of rotational states involved in a signal transition. Both progressive (a, b, and d) and regressive $(V$-type; c) arrangements are probed.

states involved in the transition ${ }^{30,32,45}$. The schemes employed in this experiment were designed to observe the optimum emission signal of a signal transition utilizing a $\pi / 2$-pulse. Changes in the population of rotational states involved in a signal transition, caused by the population inversion of the pump transition $\left(2_{02} \leftarrow 1_{01}\right)$, alters the emission signal detected. There are four signal transitions within the $2-8 \mathrm{GHz}$ frequency range that were accessible and of a decent intensity: $2_{11} \leftarrow 2_{02}, 3_{03} \leftarrow 2_{02}$, $2_{12} \leftarrow 1_{01}$ and $3_{13} \leftarrow 2_{02}$ at 3028.32, 3111.70, 3270.55, 
5049.95 and $6020.53 \mathrm{MHz}$, respectively. Figure 7 shows each of the signal transitions that we probe with the different schemes, as well as the approximate occupation for each of the states.

In scheme I we pump the $2_{02} \leftarrow 1_{01}$ transition at $2183.17 \mathrm{MHz}$ with a $\pi$-pulse that should invert the population of the two states, then probes this population inversion via a signal transition with a $\pi / 2$-pulse. In scheme II we pump the $2_{02} \leftarrow 1_{01}$ transition with a $10 \mathrm{MHz}$ broad chirp centred around the resonance frequency with a fixed pulse duration of $250 \mathrm{~ns}$. The experimental set-up of scheme II differed slightly from the set-up employed for the other schemes as it required the use of both the TWT and solid-state amplifiers. Here, the TWT amplified the $10 \mathrm{MHz}$ chirp at $100 \%$ gain to ensure that the pulse was within the RAP regime, whilst the subsequent $\pi / 2$-pulse was amplified by the solid state amplifier. RAP-pulses are considered a more robust method for population inversion and have been utilized to enhance the transfer of population ${ }^{46,47}$. Scheme III consists of only one $\pi / 2$-pulse that probes a signal transition and was applied directly after each of the 2-pulse experiments to act as a reference.

PGOPHER was used to calculate the population distribution of 4-nitroanisole at $1 \mathrm{~K}$. This is the approximate rotational temperature of a supersonically expanded sample of 4-nitroanisole seeded with neon within our experimental set-up. The signal detected when scheme III is employed depends upon the population difference of the signal transition. Should conditions allow for population inversion, the numbers calculated with PGOPHER can be used to determine the direction of intensity change measured for each of the signal transitions. According to the calculated population differences we should observe a reduction in intensity for signal transitions at $3111.70,3270.55$ and $6020.53 \mathrm{MHz}$ and an increase in intensity for the signal transition at $5049.95 \mathrm{MHz}$ when comparing the results of scheme III with I. This is corroborated by the measurements taken, refer to Fig 8. Even if the $\pi$-pulse were to invert only $85 \%$ of the population for the states involved in the pump transition the same trend would be expected. The change in intensity recorded when moving from scheme II to III also follows this trend (Fig. 9), but results in larger intensity differences. For example, for the $3_{03} \leftarrow 2_{02}$ transition at $3270.55 \mathrm{MHz}$, scheme I results in an increase in signal of approximately $37 \%$ when compared with the measured signal from scheme III, whereas scheme II recorded a $123 \%$ increase in signal from scheme III. Figure ?? in the supplementary material plots the percentage differences in intensity for each signal transition. The observed differences suggest that the RAP-pulse has enhanced the population inversion of the focus transition.

A notable difference between scheme I and scheme II is in the treatment of the $M$ substates ( $M$ being the quantum number that describes the projection of angular momentum J onto an external field axis). Strictly speaking, we only observe the average $\pi$ and $\pi / 2$ pulse durations for the manifold of $M$ substates, which results in the broadening of the nutation curves (Fig. ?? and ??). The different transition dipole moments for the $M$ components lead to different optimum durations for the excitation pulse. A $\pi$-pulse cannot address all $M$ substates involved in a rotational transition, which is different for the RAP pulse. For the RAP-pulse all the $M$ substates of the lower rotational state with counterparts in the upper rotational state that obey selections rules will be affected. The electric field vectors of scheme I and II differ because of experimental reasons. In scheme I the electric field vectors of the two pulses are parallel, thus transitions must obey the selection rule $\Delta M=0$. In scheme II, both the TWT and solid-state amplifiers are used with two inputs of a dual polarization horn antenna, so the $\Delta M= \pm 1$ selection rule applies. These differences in the treatment of the $M$ states contribute to the observed intensity differences between schemes I and II. The effect that these tailored microwave pulses have on rotational state population can be clearly observed and predicted, demonstrating their potential for selectively populating rotational states of interest.

\section{CONCLUSIONS}

We recorded the high-resolution broadband rotational spectrum of 4-nitroanisole, which is considered a typical "push-pull" molecule. The high sensitivity of the spectrometer allowed for the assignment of all the ${ }^{13} \mathrm{C},{ }^{15} \mathrm{~N}$, ${ }^{18} \mathrm{O}$ isotopologues of 4-nitroanisole. Consequently, the position of every atom within the molecule, excluding hydrogen, could be determined via Kraitchman calculations. The accuracy of the determined rotational constants also allowed for a mass-dependent least-square fitting method to be applied for structural determination. Results from the least-square fitting approach provided a much more reliable structure with reduced errors when compared to the $r_{s}$-structure obtained from Kraitchman calculations. This structure was directly compared to nitrobenzene and anisole, where the reduction in the respective $\mathrm{C}-\mathrm{N}$ and $\mathrm{C}-\mathrm{O}$ bond lengths was rationalised by the "push-pull" effect present in 4-nitroanisole.

Population transfer experiments were carried out using tailored microwave pulses. PGOPHER was used to predict the population distribution of 4-nitroanisole at $1 \mathrm{~K}$. These numbers could then be used to understand the changes in intensity of selected rotational transitions brought about by the redistribution of population via the different pulse schemes. The population of the states involved in the pump transition are altered via a $\pi$-, or a RAP-pulse. Consequently new population differences for the signal transitions were determined and the effect on the transition intensities could be predicted. The differences in the intensity recorded with the different pulse schemes confirmed the anticipated redistribution of population. This demonstrates that tailored microwaves pulses can be used to populate specific rotational states 
a)

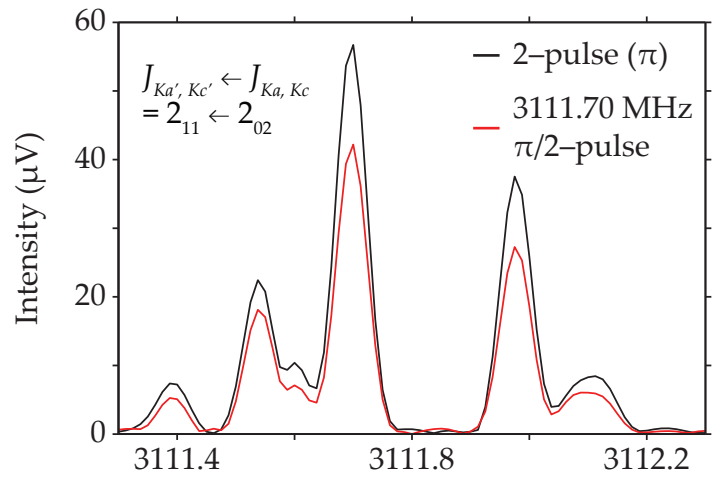

c)

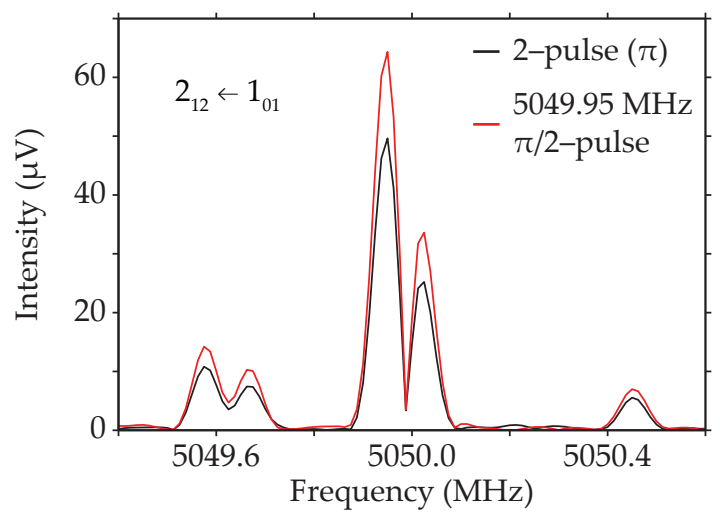

b)

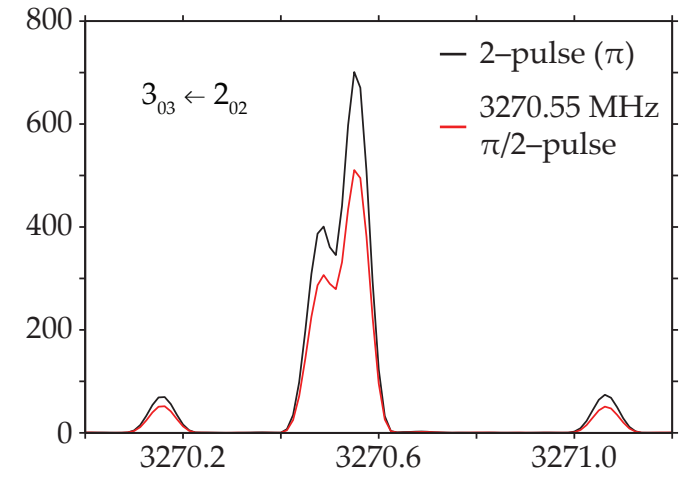

d)

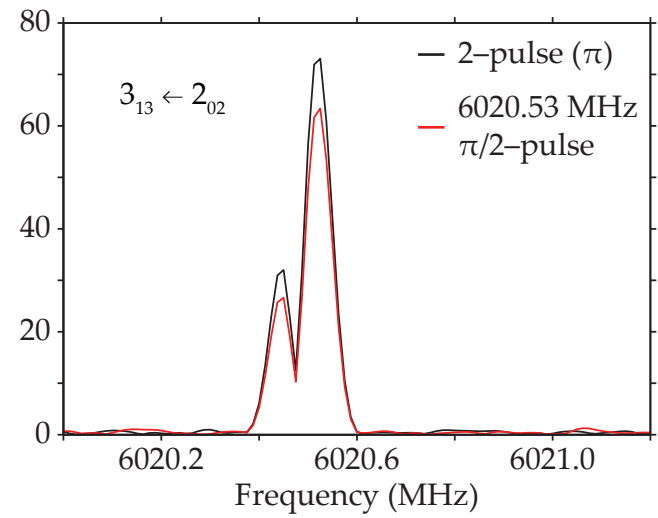

FIG. 8. Measured intensities for each of the signal transitions using single frequency microwave pulses. The black trace is the result of scheme I and the red trace the result of scheme III.

of interest. Increasing the population occupation for a state of interest would be advantageous for the motion manipulation techniques mentioned in the introduction. This is especially the case for experiments that aim to guide and decelerate larger, more complex molecules with static electric fields ${ }^{19}$ or with microwave fields ${ }^{48}$. For such examples, a larger density of rotational states, due to the relatively small rotational constants, reduces the effectiveness of the manipulation method applied. With increasing electric field strength the chance for the rotational state of interest to cross and/or avoid other rotational energy levels increases, increasing the potential for losses from a molecular packet. The use of microwave pulses to transfer more population to a state of interest would be a viable way to compensate for such losses.

\section{SUPPLEMENTARY MATERIAL}

See the supplementary material for rotational parameters determined via an MP2 calculation, nutation curves and plots of the percentage differences in intensity for each signal transition.

\section{ACKNOWLEDGEMENT}

Cristóbal Pérez is grateful for support via a postdoctoral research fellowship from the Alexander von Humboldt Foundation. We acknowledge the use of the GWDG computer cluster.

\section{KEYWORDS}

microwave spectroscopy, population transfer, pushpull molecules, structure determination

${ }^{1}$ M. Muniz-Miranda and N. Neto, "Surface-enhanced Raman scattering of $\pi$-conjugated pushpull molecules: Part I. p-nitroaniline adsorbed on silver nanoparticles," Colloids Surf. A 249, 79-84 (2004).

${ }^{2}$ M. Muniz-Miranda, "SERS investigation on the adsorption and photoreaction of 4-nitroanisole in Ag hydrosols," J. Raman Spectrosc. 44, 14161421 (2013).

${ }^{3}$ D. M. Burland, R. D. Miller, and C. A. Walsh, "Secondorder nonlinearity in poled-polymer systems," Chem. Rev. 94, 1 (1994).

${ }^{4}$ N. P. Prasad and D. J. Williams, Introduction to Nonlinear Optical Effects in Molecules and Polymers (Wiley, 1991).

${ }^{5}$ W. E. Steinmetz, "The application of low-resolution microwave spectroscopy to conformational analysis," J. Am. Chem. Soc. 96, 685-692 (1974). 
a)

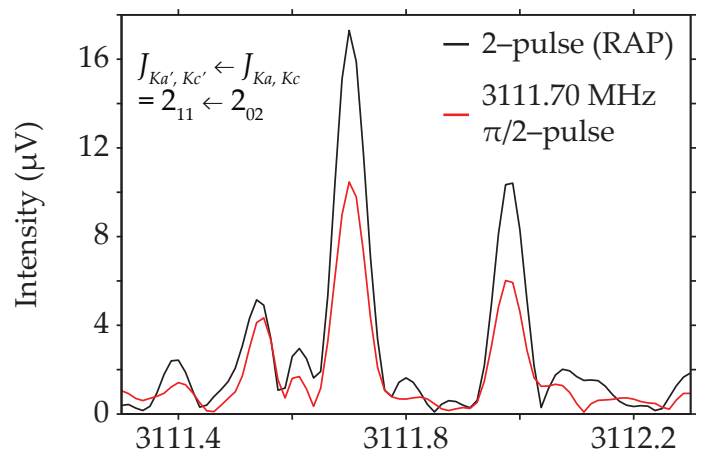

c)

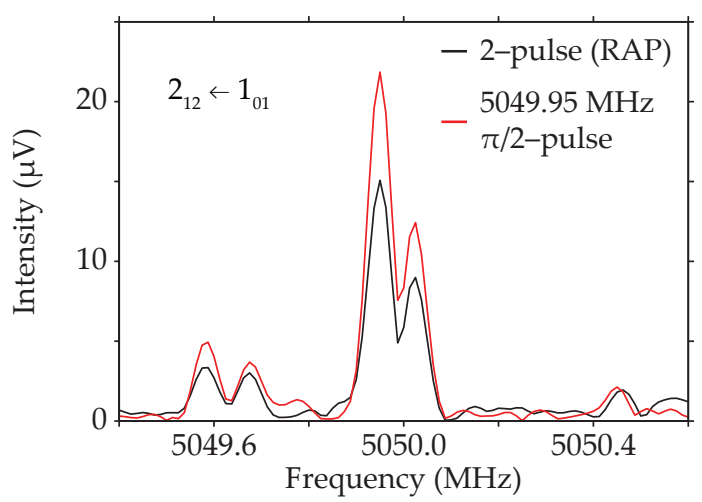

b)

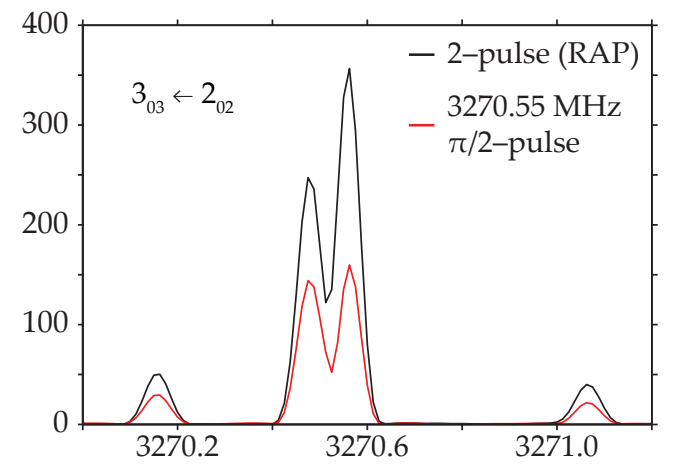

d)

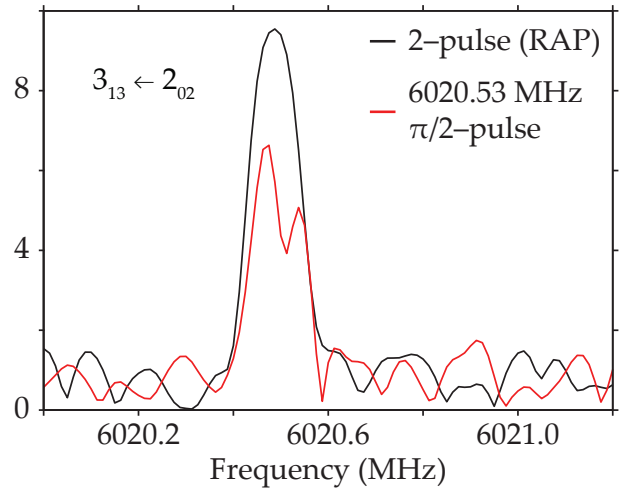

FIG. 9. Measured intensities for each of the signal transitions using a combination of single frequency pulses and $10 \mathrm{MHz}$ broad chirps. The black trace is the result of scheme II and the red trace the result of scheme III.

${ }^{6}$ S. Zinn, T. Betz, C. Medcraft, and M. Schnell, "Structure determination of trans-cinnamaldehyde by broadband microwave spectroscopy," Phys.Chem.Chem.Phys. 17 (2015).

${ }^{7}$ S. R. Domingos, C. Pérez, and M. Schnell, "Communication: Structural locking mediated by a water wire: A high-resolution rotational spectroscopy study on hydrated forms of a chiral biphenyl derivative," J. Chem. Phys. 145 (2016).

${ }^{8}$ J. H. Høg, L. Nygaard, and G. O. Sørensen, "Microwave spectrum and planarity of nitrobenzene," J. Mol. Structure 7, 111121 (1970).

${ }^{9}$ O. V. Dorofeeva et al., "Molecular structure and conformation of nitrobenzene reinvestigated by combined analysis of gas-phase electron diffraction, rotational constants, and theoretical calculations," Struct. Chem. 18, 739-753 (2007).

${ }^{10}$ M. Onda, A. Toda, S. Mori, and I. Yamaguchi, "Microwave spectrum of anisole," J. Mol. Spectrosc. 144, 47-51 (1986).

${ }^{11}$ H. L. Bethlem, B. G., and G. Meijer, "Decelerating neutral dipolar molecules," Phys. Rev. Lett. 83, 1558 (1999).

${ }^{12}$ N. Vanhaecke, U. Meier, M. Andrist, B. H. Meier, and F. Merkt, "Multistage Zeeman deceleration of hydrogen atoms," Phys. Rev. A 75 (2007).

${ }^{13}$ D. DeMille, G. D. R., and J. Petricka, "Microwave traps for cold polar molecules," Eur. Phys. J. D 31, 375384 (2004).

${ }^{14} \mathrm{~K}$. Enomoto and T. Momose, "Microwave Stark decelerator for polar molecules," Phys. Rev. A 72 (2005).

${ }^{15}$ H. Odashima, S. Merz, K. Enomoto, M. Schnell, and G. Meijer, "Microwave lens for polar molecules," Phys. Rev. Lett. 104 (2010).

${ }^{16}$ S. Y. T. van de Meerakker, H. L. Bethlem, N. Vanhaecke, and G. Meijer, "Manipulation and control of molecular beams," Chem. Rev. 112, 48284878 (2012).

${ }^{17}$ M. R. Tarbutt, H. L. Bethlem, J. L. Hudson, V. L. Ryabov, V. A. Ryzhov, B. E. Sauer, G. Meijer, and E. A. Hinds, "Slow- ing heavy, ground-state molecules using an alternating gradient decelerator," Phys. Rev. Lett. 92, 173002 (2004).

${ }^{18}$ N. E. Bulleid, R. J. Hendricks, E. A. Hinds, S. A. Meek, G. Meijer, A. Osterwalder, and M. R. Tarbutt, "Traveling-wave deceleration of heavy polar molecules in low-field-seeking states," Phys. Rev. A 86, 021404(R) (2012).

${ }^{19}$ D. Patterson, "Decelerating and trapping large polar molecules," ChemPhysChem. 17, 3790-3794 (2016).

${ }^{20}$ J. C. Keske and B. H. Pate, "Decoding the dynamical information embedded in highly mixed quantum states," Annu. Rev. Phys. Chem. 51, 323-353 (2000).

${ }^{21}$ T. Oka, "High-power microwave double-resonance experiments," Can. J. Phys. 47, 2343-2350 (1969).

${ }^{22} \mathrm{~F}$. Wodarczyk and E. Wilson, "Radio frequency-microwave double resonance as a tool in the analysis of microwave spectra," J. Mol. Spectrosc. 37, 445-463 (1971).

${ }^{23} \mathrm{~B}$. Vogelsanger, M. Andrist, and A. Bauder, "Two-dimensional correlation experiments in microwave Fourier transform spectroscopy," Chem. Phys. Lett. 144, 180-186 (1988).

${ }^{24} \mathrm{~B}$. Vogelsanger and A. Bauder, "Two-dimensional microwave Fourier transform spectroscopy," J. Chem. Phys. 92, 4101-4114 (1990).

${ }^{25}$ U. Wötzel, W. Stahl, and H. Mäder, "The influence of an offresonant pump radiation in Fourier transform microwave spectroscopy," Can. J. Phys. 75, 821-830 (1997).

${ }^{26}$ D. Schmitz, A. V. Shubert, D. Patterson, A. Krin, and M. Schnell, "Phase dependence of double-resonance experiments in rotational spectroscopy," J. Phys. Chem. Lett. 6, 1493-1498 (2015).

${ }^{27}$ D. Schmitz, A. Shubert, T. Betz, and M. Schnell, "Multiresonance effects within a single chirp in broadband rotational spectroscopy: The rapid adiabatic passage regime for benzonitrile," J. Mol. Spectrosc. 280, 7784 (2012). 
${ }^{28}$ C. Pérez, S. Lobsiger, N. A. Seifert, D. P. Zaleski, B. Temelso, G. C. Shields, Z. Kisiel, and B. H. Pate, "Broadband Fourier transform rotational spectroscopy for structure determination: The water heptamer," J. Chem. Phys. Lett. 571, 1-15 (2013).

${ }^{29}$ S. R. Domingos, C. Pérez, C. Medcraft, P. Pinacho, and M. Schnell, "Flexibility unleashed in acyclic monoterpenes: Conformational space of citronellal revealed by broadband rotational spectroscopy," Phys. Chem. Chem. Phys. 18 (2016).

${ }^{30}$ G. G. Brown, B. C. Dian, K. O. Douglass, S. M. Geyer, S. T. Shipman, and B. H. Pate, "A broadband Fourier transform microwave spectrometer based on chirped pulse excitation," Rev. Sci. Instrum. 79 (2008).

${ }^{31}$ M. J. Frisch, G. W. Trucks, H. B. Schlegel, G. E. Scuseria, M. A. Robb, J. R. Cheeseman, G. Scalmani, V. Barone, B. Mennucci, G. A. Petersson, H. Nakatsuji, M. Caricato, X. Li, H. P. Hratchian, A. F. Izmaylov, J. Bloino, G. Zheng, J. L. Sonnenberg, M. Hada, M. Ehara, K. Toyota, R. Fukuda, J. Hasegawa, M. Ishida, T. Nakajima, Y. Honda, O. Kitao, H. Nakai, T. Vreven, J. A. Montgomery, J. E. Peralta, F. Ogliaro, M. Bearpark, J. J. Heyd, E. Brothers, K. N. Kudin, V. N. Staroverov, R. Kobayashi, J. Normand, K. Raghavachari, A. Rendell, J. C. Burant, S. S. Iyengar, J. Tomasi, M. Cossi, N. Rega, J. M. Millam, M. Klene, J. E. Knox, J. B. Cross, V. Bakken, C. Adamo, J. Jaramillo, R. Gomperts, R. E. Stratmann, O. Yazyev, A. J. Austin, R. Cammi, C. Pomelli, J. W. Ochterski, R. L. Martin, K. Morokuma, V. G. Zakrzewski, G. A. Voth, P. Salvador, J. J. Dannenberg, S. Dapprich, A. D. Daniels, Farkas, J. B. Foresman, J. V. Ortiz, J. Cioslowski, and D. J. Fox, "Gaussian 09," (2009).

${ }^{32}$ J. C. McGurk, T. G. Schmalz, and W. H. Flygare, "Fast passage in rotational spectroscopy: Theory and experiment," J. Chem. Phys. 60, 4181-4188 (1974).

${ }^{33}$ J. C. McGurk, T. G. Schmalz, and W. H. Flygare, Advances in Chemical Physics (John Wiley and Sons, Inc., 1974).

${ }^{34}$ C. M. Western, "Pgopher, a program for simulating rotational structure,".

${ }^{35}$ N. Heineking and H. Dreizler, "Nitrogen quadrupole coupling constants of nitrobenzene and o-nitrophenol," Ber. Bunsenges. Phys. Chem. 97 (1993)
${ }^{36}$ J. Kraitchman, "Determination of molecular structure from microwave spectroscopic data," Amer. J. Phys. 21, 17-24 (1953).

${ }^{37}$ Z. Kisiel, "Prospe. programs for rotational spectroscopy,".

${ }^{38}$ O. Desyatnyk, L. Pszczkowski, S. Thorwirth, T. M. Krygowski, and Z. Kisiel, "The rotational spectra, electric dipole moments and molecular structures of anisole and benzaldehyde," Phys. Chem. Chem. Phys. 7 (2005).

${ }^{39}$ D. J. Millen and J. R. Morton, "The microwave spectrum of nitric acid," J. Chem. Soc. , 1523-1528 (1960).

${ }^{40}$ A. P. Cox and S. Waring, "Microwave spectrum and structure of nitromethane," J. Chem. Soc., Faraday Trans. 2 68, 1060-1071 (1972).

${ }^{41}$ J. K. G. Watson, A. Roytburg, and W. Ulrich, "Least-squares mass-dependence molecular structures," J. Mol. Spectrosc. 196 (1999).

42 A. Domenicano, G. Schultz, I. Hargittai, M. Colapietro, G. Portalone, P. George, and C. W. Bock, "Molecular structure of nitrobenzene in the planar and orthogonal conformations a concerted study by electron diffraction, X-ray crystallography, and molecular orbital calculations," Struct. Chem. 1, 107-122 (1990).

${ }^{43}$ J. H. Høg, "A study of nitrobenzene," (1971).

${ }^{44}$ J. L. Neill, S. T. Shipman, L. Alvarez-Valtierra, A. Lesarri, Z. Kisiel, and B. H. Pate, "Rotational spectroscopy of iodobenzene and iodobenzeneneon with a direct digital $28 \mathrm{ghz}$ chirpedpulse Fourier transform microwave spectrometer," J. Mol. Spec. 269, 2129 (2011).

${ }^{45} \mathrm{~J}$. Grabow, Handbook of high-resolution spectroscopy, edited by M. Quack and F. Merkt, Vol. 2 (John Wiley and Sons, 2011) p. 723801

${ }^{46}$ J. S. Melinger, S. R. Gandhi, A. Hariharan, J. X. Tull, and W. S. Warren, "Generation of narrowband inversion with broadband laser pulses," Phys. Rev. Lett. 68, 2000-2003 (1992).

${ }^{47}$ J. S. Melinger, S. R. Gandhi, A. Hariharan, D. Goswami, and W. S. Warren, "Adiabatic population transfer with frequencyswept laser pulses," J. Chem. Phys. 101, 6439-6454 (1994).

${ }^{48}$ J. B. Graneek, S. Merz, D. Patterson, T. Betz, and M. Schnell, "Simulating spatial microwave manipulation of polyatomic asymmetric-top molecules using a multi-level approach," ChemPhysChem. 17, 3624-3630 (2016). 